\title{
sciendo
}

10.2478/AMB-2020-0005

\section{DIGITAL DETERMINATION OF CURVATURE OF ROOT CANALS OF EXTRACTED TEETH}

\author{
D. Kosturkov, E. Radeva, T. Uzunov \\ Department of Conservative Dentistry, Faculty of Dental Medicine, Medical University - Sofia, Bulgaria
}

\begin{abstract}
Introduction: Determination of the curvature of root canals at present is accomplished by complicated or expensive methods. Therefore, there is a need to develop a new digital method by which this curvature can be determined quickly, easily and accurately. The aim of this in-vitro study is to determine the angles of curvature of the root canals of extracted teeth by comparing a new digital method of measurement with an established digital method. Material and Methods: Forty-eight (48) root canals of extracted teeth were studied to achieve the goal. In all roots, curvature is measured by three methods: Method 1 - new digital photographic method and special Software (Screen Protractor); Method 2 - a new digital radiography method and special software (Screen Protractor); Method 3 approved method, digital by X-ray and special Software (Durr dental). Results: The mean degrees of the measured curvature of the root canals in all three groups are similar and are about $22^{\circ}$. There are no statistically significant differences between them $(p>0.05)$. Conclusion: This shows that the new digital photographic and x-ray methods for measuring root curvature can accurately determine the curve angle for extracted teeth.
\end{abstract}

Key words: curved root canals, curvature determination, digital method

Corresponding authors: Dimitar Nikolaev Kosturkov, FDM, MU, 1 "Sveti Georgi Sofiyski" Street, 1431 Sofia, tel. +359 883445441, e-mail: D.Kosturkov@gmail.com

\section{INTRODUCTION}

ए ndodontic treatment is associated with a number of difficulties. One of the major challenges is the treatment of curved root canals. The strategies and methods of negotiating these canals depend on the degree of their curvature. The exact determination of the curve angle of the root canals is relevant to the choice of appropriate treatment method and consequently successful endodontic treatment. The presence of curvature limits the preparation in this area and this can lead to errors associated with ledge formation, instrument breakage, perforation or apex transportation [3,9]. It is extremely important to select appropriate tools and technique for root canal treatment in the course of treatment depending on its curvature [2, 14, 19]. Root canals are classified as straight when the curvature angle is $5^{\circ}$ or less, averaged curved - at an angle of $10^{\circ}-20^{\circ}$ and strongly curved - at an angle of over $20^{\circ}$.

Various methods for determining root canal curvature are described in the literature, but there is no consensus on which method to use. Some of these methods can be used in clinical practice, but others are only relevant for research purposes [9].

The following methods are used to determine the root canal curvature: X-ray (Schneider, Weine, Luiten, Cunningham and Senia methods) and CT [1, 3, 7, $11,12,13,16,20,22,23]$. Traditionally, the diagno- 
sis and planning of endodontic treatment is based on periapical X-ray. The Schneider and Weine method has been widely used in endodontics due to its easy and practical use.

Some of the available methods (CBCT, MicroCT) are expensive and involve the use of specialized, expensive software products, which further limits their use.

Determining curvature by these methods requires time and specific knowledge. Therefore, there is a need to develop a new digital method for determining root canal curvature by using affordable and easy-touse software that can be used for scientific research on extracted teeth.

\section{AIM}

The aim of this in-vitro study is to determine the angles of curvature of the root canal of extracted teeth by comparing a new digital method of measurement with an established digital method.

\section{MATERIAL AND METHODS}

To achieve the goal, 48 root canals of extracted teeth were studied.

The method by which we examined the curves is based on the Schneider method, where three points are used to determine the curvature angle, which are marked in the region of the orifice, the canal curvature and the apical foramen. After connecting the first and second points, a line is created, and a second line is drawn after the second and third points are joined. The curvature is determined by the angle between them - Fig. 1 [3, 9, 17].

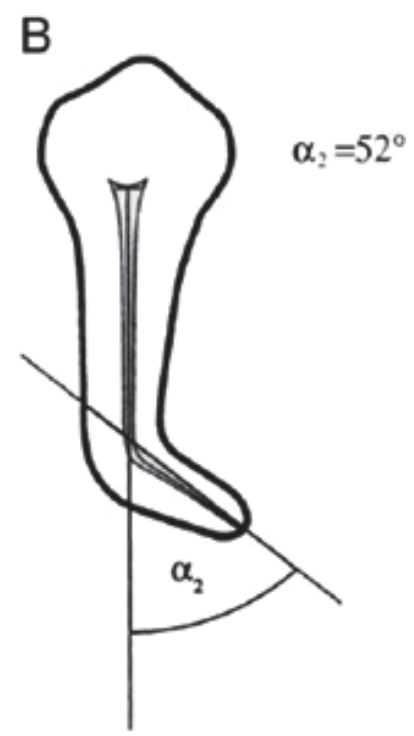

Fig. 1. Schneider's method for determination of canal curvature (by Plotino)
On all roots, curvature is measured by three methods:

1. Method 1 - a new digital photographic method and special software (Screen Protractor).

With this method, all roots are photographed using a standardized technique by Nikon D90 DSLR camera, a Nikon AF-S VR 105 mm f / 2.8G IF-ED Micro lens and a Nikon R1C1 macro flash. Each photo is taken to measure root curvature using the Screen Protractor software. The angle on the outer surface of curvature AOB is measured (Fig. 2).

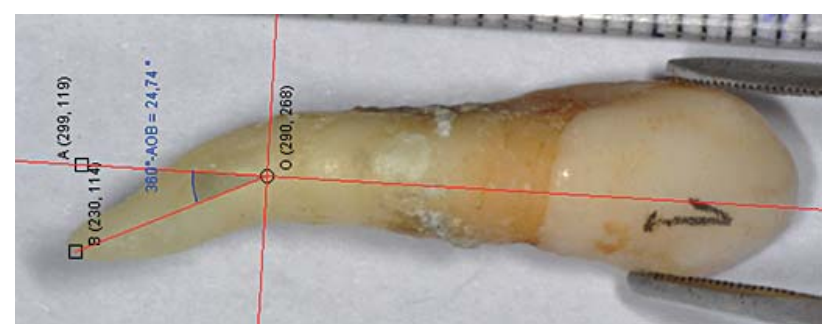

Fig. 2. Measurment of the root curvature by digital photography and specialized software Screen Protractor

2. Method 2 - a new digital X-ray method and special software (Screen Protractor).

In this method, after performing a digital radiography of the tooth, the root canal curvature is measured by specialized Screen Protractor software. The angle $A O B$ on the outer surface of the root curve is measured (Fig. 3).

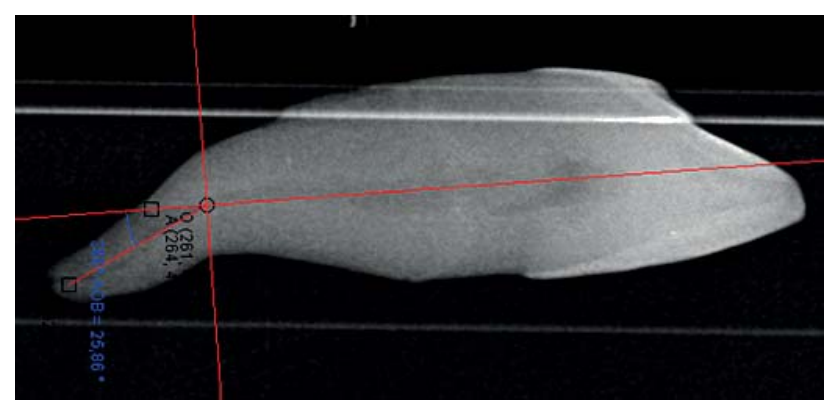

Fig. 3. Measurment of root canal curvature by digital X-ray and specialized software Screen Protractor.

3. Method 3-Approved Method, Digital by X-ray and Special Software (Durr dental).

In this method, after making a digital radiograph of the tooth, the curvature of the root canal is measured using the Durr Dental specialized software for X-ray imaging. The angle on the outer surface of the curvature is measured (Fig. 4).

After measuring the root canal curves by the three methods for each root, the results are statistically processed by IBM Statistics SPSS v. 19. A Student- 
Fisher test is applied to compare measurement values and correlation analysis to establish the relationship between root curvature and root canal curvature.

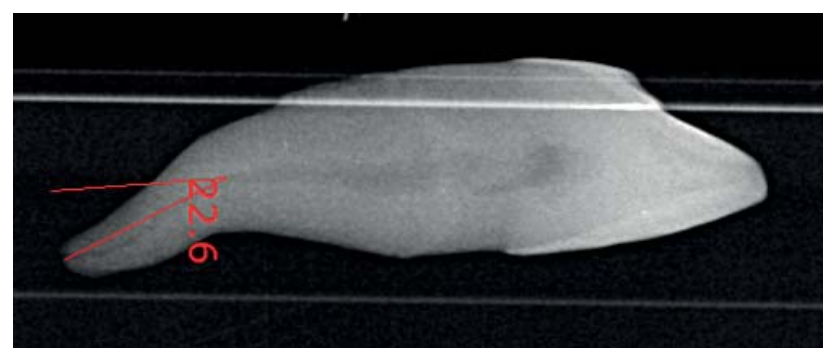

Fig. 4. Measurement of the root canal curvature by digital X-ray and specialized software Durr Dental

Depending on the method of measurement, the teeth are divided into three groups.

\section{RESULTS}

By comparing the mean values of curvature angles through the three methods, we obtained the results presented in Table 1.

The table shows that the mean degrees of the measured curvature of the root canals in all three groups are similar and are about $22^{\circ}$. There are no statistically significant differences between them ( $p$ $>0.05$ ). This shows that the new digital photographic and $\mathrm{x}$-ray methods for measuring the curvature of the root can accurately determine the curve angle.

The table shows that there is a correlation between all the studied groups. This confirms once again the accuracy and reliability of the new digital method for measuring the curvature of the root canal.

\section{DISCUSSION}

In literature, the most commonly cited method for determining the curvature of the root canal is Schneider's. This method is simplified and easy and is done by measuring the curvature of the root canal by analog X-ray and millimeter paper $[5,6,15,18,21,25]$. The X-ray image allows visualization of the curvature in the medio-distal direction but is not sufficiently informative for the curvature in the bico-lingual direction [3].

In some experimental studies involving root canal curvature, canal transportation, or instrument stress, apart from the classic curvature angle measurement techniques - Weine, LAT (long axis technique), are described techniques using highly specialized engineering software - AutoCAD or by a digital image overlay method. Work with such programs requires specific knowledge and expensive, complicated equipment [10].

Although the measurement of curvature of the root canal is very accurate, the application of these methods is difficult. This is conditioned by the specific features of the software, the knowledge of which requires extra and continuous training. Therefore, it is necessary to apply an accurate, reliable and easily executable way of measuring the root canal curvature.

In recent years, more and more digital technologies have been imposed, allowing for much more accurate measurements. Computer tomography is increasingly becoming part of everyday clinical practice $[4,7,8,9$, $16,20]$. This method determines the radius of curvature. One line follows the course of the root canal in the apical area, and the second line follows the groove in the middle and coronary. Regardless of the length of the second line, only six millimeters of the first line is measured. Each line segment is defined as the midpoint. From this

Table 1. Mean values in degrees and standard deviation of root canal curves for the three groups

\begin{tabular}{|c|c|c|}
\hline Studied group & $\begin{array}{c}\mathbf{n} \\
\text { (number of roots/canals) }\end{array}$ & $\begin{array}{c}\chi \pm \mathbf{S D} \\
\text { (degrees) }\end{array}$ \\
\hline Method № 1 (a) & 48 & $22,17 \pm 12,38$ \\
\hline Method № 2 (b) & 48 & $22,54 \pm 15,83$ \\
\hline Method № 3 (c) & 48 & $21,79 \pm 12,99$ \\
\hline & $t_{a, b}=-0,29 \quad p_{a, b}=0,77$ \\
t-test & $t_{a, c}=0,28 \quad p_{a, c}=0,78$ \\
& $t_{b, c}=0,57 \quad p_{b, c}=0,57$ \\
\hline
\end{tabular}

Table 2. Degree of correlation between the three methods of measuring the curvature of root canals

\begin{tabular}{|c|l|c|c|c|}
\hline \multicolumn{2}{|l|}{ Studied group } & Group № 1 & Group № 2 & Group № 3 \\
\hline \multirow{3}{*}{$\begin{array}{c}\text { Method } \\
\text { № } 1\end{array}$} & Pearson Correlation & 1 &, $880^{* *}$ &, $789^{\text {** }}$ \\
\cline { 2 - 5 } & Sig. (2-tailed) & &, 000 &, 000 \\
\cline { 2 - 5 } & $\mathrm{N}$ (number) & 36 & 36 & 36 \\
\hline \multirow{3}{*}{$\begin{array}{c}\text { Method } \\
\text { № } 2\end{array}$} & Pearson Correlation &, $880^{* *}$ & 1 & $865^{* *}$ \\
\cline { 2 - 5 } & Sig. (2-tailed) &, 000 & &, 000 \\
\cline { 2 - 5 } & $\mathrm{N}$ (number) & 36 & 36 & 36 \\
\hline \multirow{3}{*}{$\begin{array}{c}\text { Method } \\
\text { № 3 }\end{array}$} & Pearson Correlation &, $789^{\text {** }}$ &, $865^{\text {** }}$ & 1 \\
\cline { 2 - 5 } & Sig. (2-tailed) &, 000 &, 000 & \\
\cline { 2 - 5 } & $\mathrm{N}$ (number) & 36 & 36 & 36 \\
\hline
\end{tabular}

** Correlation is significant at levels of 0.01 (2-tailed) 
point two lines perpendicular to the first are drawn as they cross. This point is called a circumcenter. The distance between the circumcenter and the center of each line is the radius. The smaller the radius, the greater the curvature (less than $4 \mathrm{~mm}$ - a strongly curved root canal, between 4-8 mm - a medium curved root canal, and over $8 \mathrm{~mm}$ - a straight root canal). In this way, a particular segment of the root canal can be analyzed, and this is especially useful when the root has more than one curve $[3,7,8]$. However, computerized tomography is associated with a large radiation exposure for the patient and no small financial expense [3, 4, 8, 9].

For this reason, the development of a new, digital method for measuring the curvature of the root canal would facilitate the conduction of scientific research. This new digital method should provide precise, accurate, quick and easy curve measurement. Dental photography can be an essential tool in relation to this [24]. In addition, the results must be comparable to those already applied and even more precise.

The digital photographic and x-ray methods developed by us provide great accuracy and reliability in measuring the curvature of the root canal of extracted teeth. This is confirmed by studies that compare the new method to other validated digital method. The lack of a statistically significant difference and the presence of a correlation between the three groups in our study suggests that the new method can very well determine the curve of the canal. Additionally, its application is very easy, fast and is not related with expensive equipment and software products.

\section{CONCLUSION}

The new digital method we are researching to determine the root canal curvature provides very precise results that are achieved quickly and easily. This method can be used to determine the complexity of root canal anatomy of extracted teeth.

\section{Conflict of interest: The authors declared no conflict of interest}

Acknowledgements: The study is conducted under Contract № D-88/03.05.2018, CMS, MU - Sofia

Disclosure Summary: The authors have nothing to disclose.

\section{REFERENCES}

1. Arai, Y., Honda, K., Iwai, K., Shinoda, K. Practical model "3DX" of Limited cone-beam X-ray CT for dental use. Int Congr Ser 2001;1230:713-8.

2. Balani, P., Niazi, F., Rashid, H. A brief review of the methods used to determine the curvature of root canals. J Res Dent 2015;3:57-3.
3. Bhagat K. Methods for determination of root canal curvature: a brief, review. Int. J of Scientific Research, 2017, 6(6):73-5

4. Bogle, J. Endodontic treatment of curved root canal systems. Oral Health 2013;103.

5. Cheung, G., Chan, A. An in vitro comparison of the Excalibur handpiece and hand instrumentation in curved root canals. JOE, 1996, 22(3): 131-4.

6. Dagher, E., Yared, G. Comparison of three files to prepare curved canals. JOE, 1995, 21 (5); 264-5.

7. Estrela, C., Bueno M. R., Barletta F. B. et al. Identification of Apical and Cervical Curvature Radius of Human Molars. Braz Dent JI, 2015, 26(2):351-6

8. Estrela, C., Bueno, M., Sousa-Nets, M., Pécora, J. Method for determination of root curvature radius using cone-beam computed tomography images. Braz Dent J 2008;19:114-8.

9. Hartmann, R.C., Fensterseifer M., Peters O.A. et al. Methods for measurement of root canal curvature: a systematic and critical review. Int Endod J 2019 Feb;52(2):169-180. doi: 10.1111/iej.12996.

10. Hasheminia, S., Shafiee Ardestani M. The Effect of Using Patency File on Apical Transportation in Canals Prepared with Passive Step Back Technique. J Res Med Sci 2004; 5: 210-25

11. Meena, N., Kowsky, R. Applications of cone beam computed tomography in endodontics: A review. Dentistry 2014;4:242.

12. Moshiri, M., Scarfe, W., Hilgers, M. et al. Accuracy of linear measurements from imaging plate and lateral cephalometric images derived from cone-beam computed tomography. Am J Orthod Dentofacial Orthop 2007;132 (4):550-60.

13. Mounce R. Negotiating challenging mid root curvature: Rounding the bend. Dent Today 2007;26:108.

14. Mounce, R. New possibilities for managing severe curvature: The twisted file. Endo Turbine; 2008;912.

15. Nagy, C., Szabo, J., Szabo, Jz. A mathematically based classification of root canal curvatures on natural human teeth. JOE, 1995, 21 (11); 557-60.

16. Patel, S. New dimensions in endodontics imaging: Part 2. Cone beam computed tomography. Int Endod J 2009;42:463-75.

17. Plotino, G. et al. A Review of Cyclic Fatigue Testing of NickelTitanium Rotary Instruments. JOE, 2009, 35 (11):1469-76

18. Royal, J., Donnelly, J. A comparison on maintenance of canal curvature using balanced-force instrumentation with three different file types. JOE, 1995, 21 (6) 300-04.

19. Sakkir, N., Thaha, K., Nair, M. et al. Management of dilacerated and S- shaped root canals-An endodontic challenge. J Clin Diagn Res; 2014; 8:ZD22-4.

20. Scarfe, W., Levin, M., Gane, D., Farman, A. Use of cone beam computed tomography in endodontics. Int J Dent 2009; 634567.

21. Schafer, E., Tepel, J., Hoppe, W. Properties of endodontic hand instruments used in rotary motion. Part 2. Instrumentation of curved canals. JOE, 1995, 493-7.

22. Sonntag, D., Stachniss-Carp S., Stachniss V. Determination of root canal curvatures before and after canal preparation (part 1): a literature review.Aust Endod J. 2005 Dec;31(3):89-3.

23. Sonntag, D., Stachniss-Crap, S., Stachniss, C., Stachniss, V. Determination of root canal curvature before and after canal preparation (part II): A method based on numeric calculus. Aust Endod J 2006;32:16-5.

24. Uzunov, T., Kosturkov, D., Uzunov, Ts. et al. Application of photography in dental practice. JIMAB, 2015, 21 (1):682-6.

25. Weine, S. et al. Pre-curved files and incremental instrumentation for root canal enlargement. J Can Dent Assoc, 1970, 36 (4) 155-7.

Accepted: November, 2019 